\title{
A Case of Hereditary Pancreatitis Presenting as Recurrent Abdominal Pain in a 11 Year Old Girl
}

\author{
Das $\mathrm{A}^{1}$, Basu $\mathbf{M}^{2}$
}

\begin{abstract}
Recurrent abdominal pain is a common problem among children. Since its first description by John Apley in 1958, the condition has remained poorly understood with a multitude of factors being implicated in causation. The symptoms tend to be vague and investigations seldom show organic disease. But the importance to evaluate each child with recurrent abdominal pain should be considered important nevertheless, particularly, in protracted cases. Here, we present a case who presented with history of recurrent abdominal pain for several years before being diagnosed as a case of hereditary pancreatitis. This stresses the importance of evaluating each case with a detailed and complete history, physical examination and selected investigations.
\end{abstract}

Key words: Recurrent abdominal pain, Hereditary pancreatitis.

\section{Introduction}

$A_{a}^{b}$ dominal pain is a fairly common condition in children. They are often recurring, troublesome and agonising. Recurrent abdominal pain is found in approximately in $10 \%$ of school children ${ }^{1}$. The prevalence has been shown to vary in subsequent studies from $11 \%$ to $45 \% .^{2,3,4,5}$ The width of this range is probably attributable to differences in age, geographical area and social factors and methodology. An eminent British physician, John Apley, studied abdominal pain in children extensively. He coined the term recurrent abdominal pain (RAP) as abdominal pain, occurring at least three episodes, severe enough to cause functional impairment of the children over a period longer than three months.

\section{The Case}

We report a case of 11 year old girl, who presented with a history of recurrent abdominal pain since the age of four years and six months. The pain was initially of less severity and often persisted for a few hours.

The child had been treated with several medications, during this time, mainly to alleviate the acute pain. Routine blood investigations, including blood counts, serum amylase, lipase and USG abdomen was normal. Despite the management, the pain persisted and the
'Dr. Arijit Das, MBBS, DCH, MD, Assistant Professor, Department of Paediatrics, College of Medicine and JNM Hospital, Kalyani, Nadia, West Bengal, India, ${ }^{2}$ Dr. Maitreyi Basu, MBBS, DCH, MD, DNB, Professor, Department of Paediatrics, Department of Paediatrics, Bankura Samillani Medical College, Bankura, west Bengal, India.

Address for correspondence:

Dr. Arijit Das

E-mail: drarijitdas@gmail.com

\section{How to cite}

Das A, Basu M. A Case of Hereditary Pancreatitis Presenting as Recurrent Abdominal Pain in a 11 Year Old Girl. J Nepal Paediatr Soc 2015;35(1):5758.

doi: http://dx.doi.org/10.3126/jnps.v35i1.10479

This work is licensed under a Creative Commons Attribution 3.0 License.

\section{(c) (7)}

child had undergone appendicectomy at the age of seven years and six months. The pain, however, persisted, over the next few years. During this period, the child had undergone treatment with a variety of cocktail of pain medications and a battery of investigations, which this time included endoscopy with collection of bile for detecting micro-lithiasis.

The child was admitted once again at the age of 11 years with severe abdominal pain with vomiting. Blood investigation revealed an elevated serum amylase and lipase. Strikingly, a family history of 5 family members (Figure 1) with chronic pancreatitis was obtained on a detailed and careful family history. 


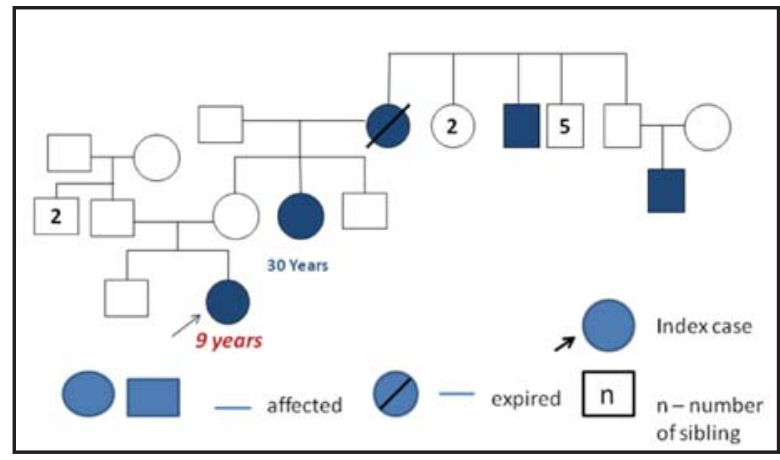

Fig 1: Pedigree chart Showing Affected members in the family.

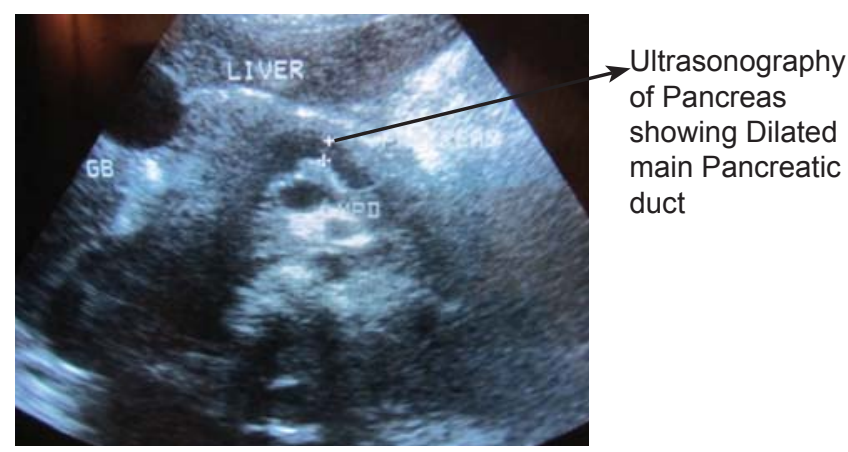

Fig 2: Ultrasonography of Pancreas showing dilated main Pancreatic duct

An USG abdomen (Figure 2) showed a dilated main pancreatic duct. A CT scan with contrast was done further, which confirmed the dilated main pancreatic duct with thinned out pancreatic tissue (Figure 3). The child was finally diagnosed as a case of hereditary pancreatitis.

\section{Discussion}

The majority of the cases of recurrent abdominal pain are thought to be due to non-organic causes. The main attributing cause is thought to be due to disordered interplay between enteric and central nervous system, termed as, functional abdominal pain. However, about $5-10 \%$ cases of RAP are due to an underlying serious organic cause ${ }^{6}$. Unfortunately, this fact is often overstressed leading to a battery of often unnecessary tests or, less often, ignoring the need to look for an underlying serious organic cause in more persistent cases.

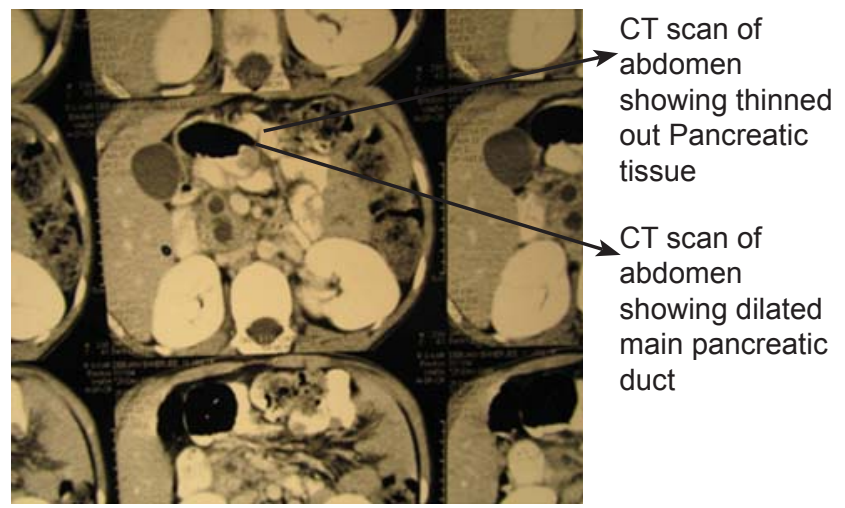

Fig 3: CT Scan of Pancreas showing dilated main pancreatic duct and thinned rim of pancreatic tissue

\section{Conclusion}

The case underscores the importance of detailed history taking and a more thorough search for organic disease, especially in protracted cases.

\section{References}

1. Apley J, Naish N. Recurrent abdominal pains: a field survey of 1000 school children. Arch Dis Child 1958;33:165-70.

2. Boey CC, Goh KL. Recurrent abdominal pain and consulting behaviour among children in a rural community in Malaysia. Dig Liver Dis 2001;33:14044 [PubMed].

3. Kokkonen J, Haapalahti M, Tikkanen S, Karttunene R, Savilahtl E. Gastrointestinal complaints and diagnosis in children: a population-based study. Acta Pediatr 2004;93:880-6 [PubMed].

4. Hyams JS, Burke G, Davis PM, Rzepski B, Andrulonis PA. Abdominal pain and irritable bowel syndrome in adolescents: a community-based study. J Pediatr 1996;129:220-26 [PubMed].

5. Boey CC, Yap SB. An epidemiological survey of recurrent abdominal pain in a rural Malay school. J Paediatr Child Health 1999;35:303-5 [PubMed].

6. Weydert JA, Ball TM, Davis MF. Pediatrics 2003;111: e1-11. 